\title{
Comparison of heating loads in residential, public and industrial buildings
}

\author{
Elena Malyavina ${ }^{1, *}$, Andrey Zdoronok ${ }^{1}$, and Daria Ozerchuk $^{1}$ \\ ${ }^{1}$ National Research Moscow State University of Civil Engineering, 26 Yaroslavskoye sh, Moscow, \\ 129337, Russian Federation
}

\begin{abstract}
Provision has been made of studying the influence of the standard thermal protection of residential, public and industrial buildings on the heating load and seasonal heat consumption for heating in various climatic conditions of the Russian Federation. The calculations have been performed on the example of a five-story building. It is proposed to economically justify the adopted standards, taking into account the cost of fuel in different regions of the Russian Federation, when revising the norms of thermal protection.
\end{abstract}

\section{Introduction}

The standards concerning the thermal protection of residential, public and industrial buildings in this country were drastically increased in the 2000s. Rationing for energysaving conditions has left far behind the heat transfer resistances required for sanitary and hygienic reasons. The risk of condensation on the inner surface of the outer enclosing structures at the average surface temperature of this surface is excluded (we are not talking about local assemblies). However, different levels of heat protection standards for residential, public and industrial buildings remained, as in the case of the regulations according to sanitary and hygienic conditions.

Of course, the norms of thermal protection are dictated not only by thermal engineering considerations. They have a significant impact on the national economy. On the one hand, a higher level of thermal protection increases the capital costs of construction, and on the other hand, it reduces the fuel consumption for heating, the power and the cost of engineering systems that serve the building, the fee for connection to heat supply networks [1].

In the articles devoted to the thermal protection of buildings, that have been recently published, a lot of problems are subject to a discussion. Modern approaches to the energy saving problem and comfortable living conditions are considered [2]. The energy efficiency and the energy saving problems include several ways to reduce the resource consumption in heating, ventilation and air conditioning systems: architectural and construction solutions, the use of renewable energy sources, optimization of microclimate systems $[3,4]$. The influence of the social aspect on the heat consumption for heating of residential buildings is mentioned in the article [5], which specifies the importance of the apartment population

* Corresponding author: emal@list.ru 
density to provide a proper assessment of the required air flow rate for ventilation. The authors $[6,7]$ believe that the most important component of the problem aimed at improving the energy efficiency of the buildings is the further perfection of regulatory and technical documents of heat engineering calculations in the modern housing construction. To increase the energy efficiency of the buildings during the reconstruction works provision should be made of the measures aimed at increasing the effect of fuel and energy resource consumption $[8,9]$. The importance of taking into account the climate factor, and a year-round one herewith, in choosing the level of thermal protection is noted in [10]. It is proposed to achieve a reduction in heat consumption in the building under reconstruction by replacing old windows with modern window structures with mandatory prevention of violations of the temperature and humidity mode at the border of the window slope and the window structure itself $[11,12,13]$ or / and by external wall thermal protection with modern mineral wool insulation materials [14]. Much attention is paid to the choice of an economically feasible thermal protection $[1,15]$.

However, since the appearance of higher standards, we have not seen a single publication justifying the need for different requirements for the thermal protection of buildings of various functional purposes in terms of the energy saving. The role of a reduced thermal protection of industrial buildings in the formation of the cost of products manufactured in these buildings is not clear, especially in conditions of constant increase in the fuel price. The purpose of this article is to clarify the influence of the thermal protection level on the heating load in various climatic conditions of the Russian Federation, that is, to prepare data for subsequent economic research. To achieve this goal, the calculated heat losses (the heating load), as well as the heat consumption for the heating of five-story buildings, where the thermal protection and the thermal mode meet the requirements of the normative standards for residential, public and industrial buildings, were determined.

\section{Materials and methods}

For a long time, the regulatory documents of the Russian Federation did not cover the method of calculating the thermal loads on heating and ventilation systems. The last time it was normalized in SNiP 2.04.05-91, and since 01.01-2004, when SNiP 41-01-2003 was put into effect, everyone used the methodology of the previous SNiP.

For the first time after a long absence, the methodology appeared in Appendix $G$ of the construction rules SP 60.13330.2016, the Amendment No. 1 edition, approved by the Order of the Ministry of Construction of the Russian Federation No. 24/pr. dated 22.01.2019. It should be clarified that the Government Decree No. 985 of July 4, 2020, which appeared later than the introduction of the Amendment No. 1 of SP 60.13330, the Annex D has not been included in the "list of national standards and codes of rules (parts of such standards and codes of rules)", mandatory for application. Subsequently, the same version of the methodology was repeated in the Draft SP 60.13330.2020. However, since it is not recognized as mandatory, the absolute majority of the designers use the methodology of SNiP 2.04.05-91, repeated mainly in MGSN 3.01-01. "Residential buildings." Moscow city building codes. The date of the entry into effect from 02.10.2001. The proposed article concerns the design heat losses and the heat consumption for heating. Therefore, it is appropriate to discuss the innovations of the SP 60.13330 .2020 methodology, and the methods used to perform the calculation in the article.

The heat resistance of several enclosing structures, the calculation results of which are given in the article, are taken from the values required by the Table 3 of SP 50.13330.2012 with the Change: $\mathrm{N} 1$ of the resistance to heat transfer. In present article, it is assumed that all heterogeneities in the enclosing structures have already been taken into account. 
The author of the method for calculating heat losses by SP 60.13330.2020 [16] suggests to proceed with regard to linear and point heterogeneities in the enclosing structures of each individual room. However, this proposal faces the difficulties of the design work procedure in this country. The heat losses are calculated by the specialists in heating, but they do not perform heat engineering calculations of enclosing structures. The Government Decree 87 "On the composition of sections of project documentation and requirements for their content", the heat protection of buildings is assigned to architects and structural designers. The Decree states that the design section 4 "Structural and space-planning solutions" should contain: "l) justification of design solutions and measures that ensure: compliance with the required thermal protection characteristics of enclosing structures". But, as it is known, the heat transfer mastering is not the specialty of architects and designers. The specialists of the "Energy Efficiency" section could fulfill the requirement, but they do heat engineering calculations of the enclosing structures throughout the whole building and, as a rule, when the heat losses have long been calculated.

The innovation of the SP 60.13330.2020 methodology is a complete elimination of additional heat losses, including for orientation and for corner rooms. The refusal to take into account different loads in rooms that are differently oriented to the cardinal directions is justified by two considerations. First, the convective part of the outer surface heat transfer of the enclosing structure is obviously overestimated by the norms, where provision is made of a high value of its heat transfer coefficient of $23 \mathrm{~W} /\left(\mathrm{m} 2 \cdot{ }^{\circ} \mathrm{C}\right)$. At the same time, the method's author [16] is familiar with the in-situ studies that note lower values. Secondly, less sun exposure to the external surfaces of the northern orientation, which leads to a greater operational humidity of the building materials behind these surfaces, is compensated by a rather high operational humidity when normalizing the thermal conductivity of the building materials according to SP 50.13330.2012. However, the additional orientation item took into account not the general increased humidity, but a higher one in the northern orientations due not only to less warming by the sun, but also due to colder northern winds [17].

The addition to the angle was eliminated due to the consideration of the linear thermal heterogeneity due to the bending of the external wall. At the same time, it is recognized in [16] that this accounting does not compensate the external face measurement conversion from external to internal one. The real lower radiation temperature of the corner rooms should be considered not by addition to the main heat losses, but the air temperature increase in the corner of the room at $2^{\circ} \mathrm{C}$, as it was done quite a while ago for residential buildings. But the SP 60.13330 .2020 methodology does not normalize this either for residential or any other functional buildings. Without taking into account the decrease in the radiation temperature at the boundary of the serviced room area, the elimination of this additive is not correct $[17,18]$.

The heat required to heat the outside air entering through the external entrance doors is taken into account in the SP 60.13330 .2020 method by calculating the infiltration heat losses. It is good that the method of calculating the load on the heating of the outside air entering the building is consistent with the method of calculating the heat consumption for these purposes for the heating season. However, the calculation requires reference data on the air resistance of entrance doors: single, double, triple with and without vestibules. These resistances in the Energy Efficiency section of the project are usually taken in the range of $0.12-0.16 \mathrm{~m} 2 \mathrm{~h} / \mathrm{kg}$ at a pressure difference of $10 \mathrm{~Pa}$, but no one can say where these estimates came from.

The five-storey building, that is subject to an investigation in this article, has dimensions of $29.78 \times 11.98 \mathrm{~m}$, with a floor height from floor to floor of $3.2 \mathrm{~m}$. The attic and basement are unheated. The floor height in residential, public and industrial buildings can be different, and the cold attics in the modern construction are used less often. 
However, to provide uniformity of the initial data for buildings of different functional purposes, these items have been assumed the same, considering that these minor discrepancies will not have a significant impact on the result of the calculations for the set goal. The height of the ventilation shaft above the attic floor is $3.9 \mathrm{~m}$. The areas of external enclosing structures and their orientation to the cardinal directions are as follows: north-east external walls $363.2 \mathrm{~m} 2$, windows $108 \mathrm{~m} 2$, entrance doors $5.28 \mathrm{~m} 2$; south-east and northwest external walls $169.18 \mathrm{~m} 2$, windows $22.5 \mathrm{~m} 2$; south-west external walls $363.2 \mathrm{~m} 2$, windows $112.5 \mathrm{~m} 2$. The ceilings above the basement and the attic floors have an area of $325.6 \mathrm{~m} 2$.

The internal air temperature of the main rooms in all buildings is assumed to be the same $20^{\circ} \mathrm{C}$, and the living rooms in the cities of Ulan-Ude and Vorkuta $21^{\circ} \mathrm{C}$. In these cities, the temperature of the coldest five-days having 0.92 sufficiency is below minus $31^{\circ} \mathrm{C}$. In the corner rooms of residential buildings, in accordance with MGSN 3.01-01, the internal air temperature is considered to be $2{ }^{\circ} \mathrm{C}$ higher than the temperature of ordinary rooms. And in public and industrial premises, an additive of 5\% is applied to the main heat losses of each vertical enclosure of the room. In accordance with GOST 30494, the temperature in the kitchens of residential buildings is set to $18^{\circ} \mathrm{C}$, in the stairwells to $14^{\circ} \mathrm{C}$. The stairwells of public and industrial buildings have a temperature of $16^{\circ} \mathrm{C}$.

The Table 1 shows the indicators of the heating period of the cities used in the calculations, for which the heating load and heat consumption for heating in the above mentioned buildings were determined. The data in the city tables are set in descending order of the calculated outdoor air temperature for heating (the lowest is the last). The heating load is affected not only by the difference in internal and external temperatures, but also by the wind speed. In the cities under consideration, the temperature of the coldest five-day period is within the range of $-2^{\circ} \mathrm{C}$ to $-41^{\circ} \mathrm{C}$. The estimated wind rate also varies widely: from $2 \mathrm{~m} / \mathrm{s}$ to $10.1 \mathrm{~m} / \mathrm{s}$. There are cities with a combination of a low design temperature and a high design wind rate (Vorkuta), and there are cities where not the lowest design outdoor temperature is combined with a fairly high design wind (Feodosiya).

Table 1. Climate characteristics of cities accepted for calculations

\begin{tabular}{|c|c|c|c|c|c|c|}
\hline $\begin{array}{c}\text { Constructio } \\
\mathrm{n} \text { region }\end{array}$ & $\begin{array}{c}\text { Air } \\
\text { temperature } \\
\text { of the } \\
\text { coldest 5- } \\
\text { day period, } \\
{ }^{\circ} \mathrm{C}\end{array}$ & $\begin{array}{c}\text { Average air } \\
\text { temperature } \\
\text { of the heating } \\
\text { season, } \\
{ }^{\circ} \mathrm{C}\end{array}$ & $\begin{array}{c}\text { Duration of the } \\
\text { heating season, } \\
\text { days }\end{array}$ & $\begin{array}{c}\text { Design } \\
\text { wind } \\
\text { rate, } \mathrm{m} / \mathrm{s}\end{array}$ & $\begin{array}{c}\text { Average wind } \\
\text { rate, m/s, of the } \\
\text { period with the } \\
\text { average daily } \\
\text { temperature } \\
\leq 8{ }^{\circ} \mathrm{C}\end{array}$ & $\begin{array}{c}\text { Degree-day } \\
\text { of the } \\
\text { heating } \\
\text { season, } \\
{ }^{\circ} \mathrm{C} \cdot \text { day/year }\end{array}$ \\
\hline Sochi & -2 & 6,6 & 94 & 2,5 & 3,5 & 1259 \\
\hline Feodosiya & -12 & 3,6 & 135 & 5,4 & 5 (for Kerch) & 2214 \\
\hline Moscow & -25 & $-2,2$ & 205 & 2 & 2 & 4551 \\
\hline Magadan & -29 & $-7,5$ & 279 & 4,8 & 3,9 & 7972 \\
\hline Ulan-Ude & -35 & $-10,3$ & 230 & 2,1 & 1,9 & 6969 \\
\hline Vorkuta & -41 & $-9,1$ & 306 & 10,1 & 5,8 & 8905 \\
\hline
\end{tabular}

It should be noted that the cities, which are listed by the descending number of the daily degree periods (GSOP) in the heating period, are not followed by the descending average temperature of the coldest five-day period and even the average temperature of the heating period, since the duration of the heating period still matters.

For a structure of a certain functional purpose, the required heat transfer resistance of each enclosing structure, except for the entrance door to the building, depends only on the value of the GSOP. For the building entrance doors, the temperature of the coldest five-day 
period is decisive. The Table 2 shows the heat transfer resistances of all external enclosing structures, as well as the window air permeability resistances.

Table 2. Thermal engineering characteristics of external enclosing structures

\begin{tabular}{|c|c|c|c|c|c|}
\hline \multirow[b]{2}{*}{$\begin{array}{l}\text { Construction } \\
\text { region }\end{array}$} & \multicolumn{4}{|c|}{ Reduced heat transfer resistance, $\mathrm{m}^{2} \cdot{ }^{\circ} \mathrm{C} / \mathrm{W}$} & \multirow{2}{*}{$\begin{array}{c}\text { Calculated } \\
\text { resistance to } \\
\text { air } \\
\text { permeability of } \\
\text { windows, } \\
\mathrm{m}^{2} \cdot \mathrm{h} / \mathrm{kg} \text {, when } \\
\Delta \mathrm{P}=10 \mathrm{~Pa}\end{array}$} \\
\hline & $\begin{array}{c}\text { External } \\
\text { walls }\end{array}$ & Windows & $\begin{array}{l}\text { Flooring above } \\
\text { the basement } \\
\text { and the attic } \\
\text { flooring }\end{array}$ & The building entrance door & \\
\hline \multicolumn{6}{|c|}{ Residential building } \\
\hline Sochi & 1,84 & 0,49 & 2,47 & 0,38 & 0,24 \\
\hline Feodosiya & 2,17 & 0,50 & 2,89 & 0,55 & 0,39 \\
\hline Moscow & 2,99 & 0,66 & 3,95 & 0,77 & 0,37 \\
\hline Magadan & 4,09 & 0,747 & 5,35 & 0,85 & 0,47 \\
\hline Ulan-Ude & 3,84 & 0,74 & 5,04 & 0,95 & 0,43 \\
\hline Vorkuta & 4,52 & 0,76 & 5,91 & 1,05 & 0,80 \\
\hline \multicolumn{6}{|c|}{ Public building } \\
\hline Sochi & 1,58 & 0,49 & 1,74 & 0,34 & 0,24 \\
\hline Feodosiya & 1,86 & 0,50 & 2,07 & 0,49 & 0,39 \\
\hline Moscow & 2,57 & 0,66 & 2,89 & 0,69 & 0,37 \\
\hline Magadan & 3,59 & 0,75 & 4,09 & 0,75 & 0,47 \\
\hline Ulan-Ude & 3,29 & 0,74 & 3,74 & 0,84 & 0,43 \\
\hline Vorkuta & 3,87 & 0,76 & 4,42 & 0,93 & 0,80 \\
\hline \multicolumn{6}{|c|}{ Industrial building } \\
\hline Sochi & 1,25 & 0,23 & 1,25 & 0,22 & 0,15 \\
\hline Feodosiya & 1,44 & 0,26 & 1,44 & 0,32 & 0,25 \\
\hline Moscow & 1,91 & 0,31 & 1,91 & 0,44 & 0,23 \\
\hline Magadan & 2,59 & 0,40 & 2,59 & 0,48 & 0,29 \\
\hline Ulan-Ude & 2,39 & 0,37 & 2,39 & 0,54 & 0,27 \\
\hline Vorkuta & 2,78 & 0,42 & 2,78 & 0,60 & 0,50 \\
\hline
\end{tabular}

The latter are equal for residential and public buildings because the normalized transverse air permeability of the windows in plastic or aluminum bindings for the buildings of both purposes is limited from above by the same value of $5 \mathrm{~kg} /\left(\mathrm{m}^{2} \cdot \mathrm{h}\right)$. For industrial buildings, the limit is $8 \mathrm{~kg} /\left(\mathrm{m}^{2} \cdot \mathrm{h}\right)$. Therefore, the required air permeability resistance of windows in industrial buildings is significantly lower. The air permeability resistance of the entrance doors of buildings of all functional purposes is set at the level of $0.16 \mathrm{~m}^{2} \cdot \mathrm{h} / \mathrm{kg}$ with $10 \mathrm{~Pa}$ difference of the external and internal air pressures.

It is interesting to note that the heat transfer resistance of all enclosing structures, except for windows and entrance doors, consistently decrease from residential buildings to industrial buildings very significantly. The norms of thermal protection of massive external enclosing structures have not changed since 2000. However, the logical relationship of these norms for buildings of different functional purposes, different GSOP gradations and various enclosing structures has either never been published, or has been lost for centuries. And it should be published in textbooks, since universities should train engineers, not artisans.

The heat resistances of the building entrance doors of residential buildings are greater than in public ones. It is explained by the values of normalized temperature difference between the inside air temperature and the temperature of the inner surface of the outer 
wall, which turn out to be standing in the denominator during calculations. In residential buildings, this value is $4^{\circ} \mathrm{C}$, and in public buildings, it is $4.5^{\circ} \mathrm{C}$. Different requirements to the temperature on the inner surface of the external enclosing structures in residential and public buildings do not cause objections. The rejection is caused by the fact that the approaches to the regulation of the building thermal protection have been dramatically processed for only one type of the enclosing structures, i.e. the windows. As for the windows, the heat transfer resistances of residential and public buildings after the processing of the norms are equal.

Different standards of thermal protection for the buildings of different purposes can be an obstacle when changing the functional purpose of the building, which is sometimes required.

\section{Results}

The Table 3 shows the building design heat losses through each enclosing structure. The difference in transmission heat loss through the windows of residential and public buildings is explained by the lower temperature of the internal air in the kitchens.

Table 3. The structure of heat losses of the buildings

\begin{tabular}{|c|c|c|c|c|c|c|c|c|}
\hline \multirow[b]{2}{*}{$\begin{array}{l}\text { Construction } \\
\text { region }\end{array}$} & \multicolumn{5}{|c|}{ Transmission, $\mathrm{W}$, through } & \multicolumn{3}{|c|}{ Infiltration, $\mathrm{W}$, through } \\
\hline & walls & windows & $\begin{array}{c}\text { Entrance } \\
\text { doors }\end{array}$ & $\begin{array}{c}\text { Attic } \\
\text { flooring }\end{array}$ & $\begin{array}{l}\text { Flooring } \\
\text { above } \\
\text { basement }\end{array}$ & windows & $\begin{array}{c}\begin{array}{c}\text { Entrance } \\
\text { doors }\end{array} \\
\text { according } \\
\text { to SP } 60\end{array}$ & 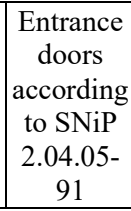 \\
\hline \multicolumn{9}{|c|}{ Residential building } \\
\hline Sochi & 13668 & 12353 & 244,40 & 2185,67 & 1457,11 & 3652,6 & 123,69 & 1193,12 \\
\hline Feodosiya & 16784 & 17596 & 274,56 & 2727,97 & 1818,65 & 7578,5 & 253,53 & 1340,35 \\
\hline Moscow & 17081 & 19045 & 294,47 & 2813,84 & 1875,89 & 6154,6 & 470,05 & 1437,53 \\
\hline Magadan & 13590 & 18423 & 294,70 & 2263,32 & 1508,88 & 9030,9 & 546,92 & 1438,66 \\
\hline Ulan-Ude & 16445 & 21078 & 298,82 & 2723,98 & 1815,99 & 7484,5 & 671,12 & 1458,79 \\
\hline Vorkuta & 15468 & 22866 & 303,47 & 2575,29 & 1716,86 & 16926 & 805,97 & 1481,48 \\
\hline \multicolumn{9}{|c|}{ Public building } \\
\hline Sochi & 15955 & 12422 & 310,07 & 3073,79 & 2049,19 & 3652,6 & 129,72 & 1513,70 \\
\hline Feodosiya & 19715 & 17922 & 331,60 & 3776,39 & 2517,59 & 7578,5 & 261,36 & 1618,81 \\
\hline Moscow & 20196 & 19087 & 345,29 & 3825,44 & 2550,30 & 6154,6 & 479,60 & 1685,62 \\
\hline Magadan & 15714 & 18540 & 348,04 & 2948,51 & 1965,68 & 9030,9 & 556,92 & 1699,05 \\
\hline Ulan-Ude & 19263 & 21106 & 351,41 & 3624,27 & 2416,18 & 7484,5 & 681,71 & 1715,52 \\
\hline Vorkuta & 18168 & 22823 & 354,12 & 3405,96 & 2270,64 & 16926 & 817,09 & 1728,76 \\
\hline \multicolumn{9}{|c|}{ Industrial building } \\
\hline Sochi & 20109 & 26488 & 482,33 & 4274,16 & 2849,44 & 5844,1 & 129,72 & 2354,64 \\
\hline Feodosiya & 25473 & 35443 & 515,82 & 5430,85 & 3620,56 & 12125 & 261,36 & 2518,15 \\
\hline Moscow & 27122 & 40236 & 537,11 & 5793,34 & 3862,23 & 9847,3 & 479,60 & 2622,08 \\
\hline Magadan & 21754 & 34811 & 541,39 & 4648,50 & 3099,00 & 14449 & 556,92 & 2642,96 \\
\hline Ulan-Ude & 26481 & 41719 & 546,64 & 5661,16 & 3774,10 & 11975 & 681,71 & 2668,59 \\
\hline Vorkuta & 25293 & 40992 & 550,86 & 5409,30 & 3606,20 & 27082 & 817,09 & 2689,18 \\
\hline
\end{tabular}

It is interesting to note that, despite the significant discrepancy in the calculated values of the outdoor air temperature, the calculated transmission heat loss through the external 
walls, the floors over unheated basements and attic floors in Magadan is less, not only than in Moscow, but also in Feodosiya. This situation is explained by the ratio of the required heat transfer resistances of the homonymous enclosing structures selected according to the GSOP in different cities.

The estimated wind rate also plays a significant role in the formation of the heat demand for heating the infiltrated air entering through the windows. For example, in Feodosiya, these heat losses are more significant than in Ulan-Ude.

The methods of SNiP 2.04.05-91 and SP 60 for calculating the heat consumption for heating the air entering the premises through leaks in the windows are the same. The infiltration heat losses through the building entrance double doors with a vestibule for heating the air entering the building are calculated according to the SNiP method by adding $0.27 \mathrm{~N}$ to the main heat losses, where $\mathrm{H}$ is the height from the ground to the top of the ventilation shaft. The calculation according to the SP 60 method is made taking into account the calculated air pressure difference formed under the influence of thermal and wind pressures on the outer and inner surfaces of the entrance doors and their resistance to the air permeability. In this article, total heat losses comprise the infiltration ones according to the current standards of SP 60 . In the buildings of all three functional purposes, the same resistance to air permeability of the entrance doors is accepted, but due to the different temperatures in the stairwells, the infiltration heat loss through the building entrance doors in residential buildings is slightly less than in public and industrial ones.

In the SP 60 methods, the infiltration heat loss through the front doors only affects the aerodynamic characteristics of the doors and the design outdoor temperature, while in the old methodology, also the resistance to heat transfer that is not true. Therefore, the heat losses for heating the air rushing through the doors, calculated according to the old method, were significantly overestimated. The new method takes into account both the outside air temperature and the wind rate, which is noticeable when comparing the infiltration heat losses in Sochi and Feodosiya, as well as in Ulan-Ude and Vorkuta.

The structure of heat losses through separate enclosing structures, shown in Table 3, indicates that the infiltration heat loss through the windows exceeds the sum of transmission losses through the floors above the unheated basement and the attic in all the cities under consideration, regardless of the estimated wind speed. At the same time, it should be noted that the air permeability resistances of the windows are taken according to the calculation of the required values, based on the window normalized air permeability. The windows used in the modern construction are often tighter than those given in the article.

The Table 4 shows the calculated heat losses due to the heat transfer, as well as infiltration heat losses. In addition, the Table 4 shows the heat consumption for heating the building during the heating season.

If we compare the listed cities in descending order of calculated total heat losses and the total heat consumption, we have to note that there are differences. In the list of cities ranked in the descending order of heat consumption, Magadan is the second city for the buildings of various functional purposes, while Ulan-Ude is the second city in terms of calculated heat losses.

In the considered cities, the buildings of one functional purpose have the ratio of the highest heating load to the lowest one in the range of $1.72-1.8$, while the ratio of seasonal heat consumption is $3.52-3.63$. At the same time, the average ratio of the heating load in one city for buildings of different purposes and the average ratio of seasonal heat consumption are very close to each other and make (industrial to public) 1.6, (public to residential) 1.1 . 
Table 4. Calculated heat losses of the building and heat consumption for heating

\begin{tabular}{|c|c|c|c|c|c|c|}
\hline \multirow{2}{*}{$\begin{array}{l}\text { Construction } \\
\text { region }\end{array}$} & \multicolumn{3}{|c|}{ Calculated heat losses, W } & \multicolumn{3}{|c|}{ Seasonal heat consumption, $\mathrm{kW} \cdot \mathrm{h}$} \\
\hline & Transmission & Infiltration & G.Total & Transmission & Infiltration & G.Total \\
\hline \multicolumn{7}{|c|}{ Residential building } \\
\hline Sochi & 29908,33 & 3776,30 & 33684,62 & 42256,26 & 6347,81 & 48604,1 \\
\hline Feodosiya & 39201,55 & 7832,06 & 47033,61 & 66789,88 & 10697,32 & 77487,2 \\
\hline Moscow & 41111,68 & 6624,65 & 47736,33 & 101617,48 & 10177,79 & 111795 \\
\hline Magadan & 36080,77 & 9577,85 & 45658,62 & 142333,29 & 25392,55 & 167725 \\
\hline Ulan-Ude & 42362,99 & 8155,66 & 50518,65 & 128959,80 & 15173,54 & 144133 \\
\hline Vorkuta & 42929,69 & 17732,44 & 60662,13 & 149660,48 & 26852,49 & 176512 \\
\hline \multicolumn{7}{|c|}{ Public building } \\
\hline Sochi & 33811,22 & 3846,18 & 37657,40 & 48556,67 & 6347,81 & 54904,5 \\
\hline Feodosiya & 44263,41 & 7960,91 & 52224,32 & 75557,08 & 10697,32 & 86254,3 \\
\hline Moscow & 46004,22 & 6723,76 & 52727,98 & 114892,83 & 10177,79 & 125070 \\
\hline Magadan & 39517,26 & 9726,40 & 49243,66 & 156329,96 & 25392,55 & 181722 \\
\hline Ulan-Ude & 46761,86 & 8267,84 & 55029,70 & 144368,49 & 15173,54 & 159542 \\
\hline Vorkuta & 47023,21 & 18080,62 & 65103,83 & 166289,69 & 26852,49 & 193142 \\
\hline \multicolumn{7}{|c|}{ Industrial building } \\
\hline Sochi & 54203,38 & 5973,89 & 60177,27 & 76832,32 & 10137,32 & 86969,6 \\
\hline Feodosiya & 70484,22 & 12387,01 & 82871,24 & 119362,79 & 16664,87 & 136027 \\
\hline Moscow & 77551,09 & 10326,97 & 87878,06 & 191882,51 & 16358,40 & 208240 \\
\hline Magadan & 64854,30 & 15006,40 & 79860,70 & 255919,98 & 41127,25 & 297047 \\
\hline Ulan-Ude & 78181,94 & 12656,97 & 90838,91 & 240241,71 & 24143,01 & 264384 \\
\hline Vorkuta & 75852,39 & 27899,45 & 103751,8 & 268066,58 & 42933,06 & 310999 \\
\hline
\end{tabular}

A comparison of the ratios of the heating system loads and the seasonal heat consumptions for heating the buildings of various purpose, taking into account the accepted heat engineering standards, did not reveal anything unusual: in residential buildings, this load is the lowest, and in industrial buildings it is the highest. Moreover, in industrial buildings, the increase in load in comparison with residential buildings increases by $1.75-$ 1.86 times. It is impossible to say unequivocally that this state of affairs is economically advantageous without conducting special studies.

A comparison of the calculated heat losses calculated according to the method of SNiP 2.04. 05-91 and according to the method of SP 60.13330-2020 showed that they fit into the range of 7.1-10\%. We can, of course, say that the accuracy of the engineering calculation should just fit into this range. Only we are not talking about comparing the calculation with a full-scale study, but about comparing the results of the calculation using two methods. This discrepancy is systematic in the direction of reducing the calculated heat losses due to the rejection of additive values to the heat losses.

\section{Conclusions}

1. Various standards of thermal protection of the buildings of different functional purposes complicate the building design procedure and in some cases can be an obstacle when changing the purpose of the building. 
2. It is necessary to economically justify the adopted approaches to the regulation of the thermal protection in the buildings of different purposes.

3. Despite the prevailing opinion that the required heat transfer and air permeability resistances of the enclosing structures are normalized based on an attempt to equalize the heat consumption for heating in various regions of the Russian Federation, it is clear that there is still a lot of work to do in this direction. Although, perhaps, it is not necessary to equalize, but the norms should take into account the cost of fuel in different regions of the Russian Federation.

4. It is advisable to coordinate the approach to the choice of the thermal protection of external doors with the approach to the selection of thermal insulation of the other enclosing structures and provide reference data of the actual resistance to the air permeability of the entrance doors having or not having the vestibules.

5. The method of calculating the heat losses should take into account an additional increase in heat losses by increasing the calculated temperature of the corner room or by adding to the main heat losses, not because of the curvature of the outer wall.

6. It is also necessary to reintroduce the additive values of the cardinal direction orientation in the method of heat loss calculation, since they take into account the different humidity of the building materials of the walls facing on different sides.

\section{References}

1. E.G. Malyavina, A.A. Frolova, News of Higher Educational Institutions. Construction 9, 56-65 (2018)

2. A. Martínez-Molina, I. Tort-Ausina, Renewable and Sustainable Energy Reviews 61, 70-85 (2016)

3. V.I. Lysev, A.S. Shilin, Scientific Journal of NRU ITMO. Series Refrigeration and air conditioning 2/3, 18-25 (2017) DOI:10.17586/2310-1148-2017-10-2/3-18-25

4. A.I. Sereguin, Energy saving 8, 78-87 (2020)

5. A.I. Ananev, A.G. Rymarov, E.V. Voitovich, A.P. Latushkin, Proceedings of Moscow State University of Civil Engineering 12(7), 741-746 (2017) DOI: 10.22227/19970935.2017.7.741-746

6. N.A. Stashevskaya, A.P. Minina, System technologies 23, 47-50 (2017)

7. A.E. Piir, O.A. Kozak, L.M. Agafonov, Energy. Bull. of High school institutions and Energy associations of the CIS, 69 -76 (2015)

8. A.N. Leonova, M.V. Kurochka, Proceedings of Moscow State University of Civil Engineering 13(7), 805-813 (2018) DOI: 10.22227/1997-0935.2018.7.805-813.

9. S.N. Osipov, V.M. Pilipenko, Energy. Bull. of High school institutions and Energy associations of the CIS 60(1), 77-96 (2017) DOI: 10.21122/1029-7448-2017-60-1-7796.

10. E.G. Malyavina, A.A. Frolova, Agricultural Scientific Journal 10, 111-114 (2020) DOI: 10.28983/asj.y2020i10pp111.114

11. A.E. Piir, O.A. Kozak, V.B. Kuntysh, Science and technology 16(2), 113-118 (2017) DOI: $10.21122 / 2227-1031-2017-16-2-113-118$

12. Ja. Viholo, Ja. Sorri, Ju. Heljo, P. Kero, Procedia Economics and Finance 21, 601-608 (2015)

13. O.V. Matekhina, Yu.K. Osipov, Bulletin of the Siberian State Industrial University 1(11), 50-55 (2015) 
14. M.I. Bzhakhov, L.T. Kardanov, M.A. Kuchukov, E.A. Antipova, A.Kh. Luyev, Engineering Bulletin of the Don 2, 3544 (2016)

15. Yu.I. Tolstova, Collection of conference proceedings. Energy saving and energy efficiency at industrial enterprises and in housing and communal services, 188-194 (2017)

16. A.Yu. Neklyudov, Residential building 7, 11-14 (2016)

17. A.N. Skanavi, Structural designing and calculation of the systems of water and air heating of the buildings (Stroyizdat, $304 \mathrm{p}, 1983$ )

18. E.G. Malyavina, N.P. Umnyakova. Textile Industry Technology 2, 291-296 (2017) 